\title{
Patterns of care and survival for patients aged under 40 years with bone sarcoma in Britain, 1980-1994
}

\author{
CA Stiller ${ }^{*, 1}$, SJ Passmore', ME Kroll', PA Brownbill', JC Wallis' and AW Craft ${ }^{2}$ \\ 'Childhood Cancer Research Group, University of Oxford, 57 Woodstock Road, Oxford OX2 6HJ, UK; ${ }^{2}$ Sir James Spence Institute of Child Health, Royal \\ Victoria Infirmary, Newcastle upon Tyne NEI 4LP, UK
}

The purpose of the study was to calculate population-based survival rates for osteosarcoma (OS) and Ewing's sarcoma (ES) in Great Britain during 1980-1994, determine proportions of patients treated at specialist centres or entered in national and international clinical trials, and investigate effects of these factors on survival. Data on a population-based series of I 349 patients with OS and 849 with ES were compiled from regional and national cancer registries, UK Children's Cancer Study Group, regional bone tumour registries and clinical trials. Follow-up was through population registers. Survival was analysed by actuarial analysis with log-rank tests and by Cox's proportional hazards analysis. Five-year survival rates during 1980-1984, 1985- 1989 and 1990-1994 were 42\% (95\% Cl: 37, 46), 54\% (95\% Cl: 50, 59) and 53\% (95\% Cl: 48, 57), respectively, for OS and 31\% (95\% Cl: 26, 37), 46\% (95\% Cl: 40, 5 I) and 5 I\% (95\% Cl: 45, 57) for ES. Proportions of patients treated at a supraregional bone tumour centre or a paediatric oncology centre in the three quinquennia were 36, 56 and 67\% for OS and 41, 60 and 69\% for ES. In 1983-1992, 48\% of OS patients were entered in a national trial; for ES, 27\% were entered in 1980- 1986 and 54\% in 1987-1994. Survival was similar for trial and nontrial patients with OS. For ES, trial patients had consistently higher 5-year survival than nontrial patients: 1980-1986, 42 vs 30\%; 1987-1992, 59 vs 42\%; 1993-1994, 54 vs 43\%. During 1985-1994, patients with OS or ES whose main treatment centre was a nonteaching hospital had lower survival rates. In multivariate analyses of patients diagnosed during 1985-1994 that also included age, sex, primary site, surgical treatment centre, the results relating to main treatment centre for both OS and ES retained significance but the survival advantage of trial entry for ES became nonsignificant. For both OS and ES diagnosed since 1985, patients whose main treatment centre was a nonspecialist hospital had a lower survival rate.

British Journal of Cancer (2006) 94, 22-29. doi:I0.1038/sj.bjc.6602885 www.bjcancer.com

Published online 29 November 2005

(c) 2006 Cancer Research UK

Keywords: osteosarcoma; Ewing's sarcoma; survival; patterns of care

Among persons aged under 40 years, osteosarcoma (OS) and Ewing's sarcoma (ES) are the most frequently occurring malignant bone tumours (Draper, 1985; Hartley et al, 1991). Some cases of chondrosarcoma also occur, although this is usually a low-grade tumour often curable by surgery alone.

Survival rates for children aged under 15 years in Great Britain have improved substantially (Stiller, 1994). For OS, two-year actuarial survival increased from $45 \%$ in $1980-82$ to $68 \%$ in $1989-$ 91, while for ES there was an improvement from 55 to $85 \%$ over the same period.

Adults with OS have a worse prognosis than children (Hartley et al, 1992). In a national study of cancer survival trends in England and Wales, five-year relative survival rates for adults with bone cancer diagnosed during 1971-1975, 1976-1980, 1981-1985 and 1986-1990 were 29, 36, 40 and 51\%, respectively (Coleman

\footnotetext{
*Correspondence: CA Stiller, Childhood Cancer Research Group, 57 Woodstock Road, Oxford, OX2 6HJ, UK;

E-mail: charles.stiller@ccrg.ox.ac.uk

Presented in part at Third International Conference on Cancer and the Adolescent, London, 2004.

Received 21 February 2005; revised 17 October 2005; accepted 30 October 2005; published online 29 November 2005
}

et al, 1999). These results were for all patients aged 15 years and over, however, and did not distinguish between histological types.

In England and Wales, age-standardised mortality from all malignant bone tumours (ICD 170) at age 10-19 years (based on a uniform population) fell from 8.9 per million in $1981-1984$ to 5.7 in 1989-1992, a decrease of 36\%, whereas at age $20-44$ years it fell from 2.9 per million in 1981-84 to 2.7 in 1989-92, a decrease of only $6 \%$. As there is no evidence for any substantial change in incidence, and allowing for the interval between diagnosis and death (among children, most deaths from bone cancer occur at 12 years after diagnosis though there is substantial further mortality for some years after), these results strongly suggest that the improvements in survival from bone sarcoma in children which took place during the 1980 s extended to patients diagnosed at up to age 17 or 18 years. For older patients, however, there is little evidence from mortality data that there has been any improvement in survival.

There was a substantial improvement in the survival of children with OS in Britain between the late 1970s and mid 1980s (Stiller and Bunch, 1990) and this was concentrated among children treated at paediatric oncology centres, who during 1981-1984 had a significantly higher survival rate than those treated elsewhere (Stiller, 1988). For children with ES, there was little change in national survival rates over the same period (Stiller and Bunch, 1990), but throughout 1977-1984 there was a significantly higher 
survival rate among children treated at paediatric oncology centres (Stiller, 1988).

The only published study of patterns of care and survival from bone tumours in adults concerned patients with OS from the South Thames Regions of England registered during 1963-82, almost entirely before the more recent increase in survival of young patients associated with more effective chemotherapy (Gill et al, 1988). The effect of entry to trials on survival from bone sarcoma has not previously been assessed.

The objectives of the present study were to calculate populationbased survival rates for OS and ES among patients aged under 40 years; to determine why the marked decrease in bone cancer mortality among the population aged under 20 years has not been seen in the 20-39 year age group; to determine the proportion of patients treated at specialist centres or entered in clinical trials and to investigate the effects of these factors on survival.

\section{PATIENTS AND METHODS}

Virtually all patients aged under 15 years at diagnosis were already included in the National Registry of Childhood Tumours (NRCT) (Stiller et al, 1995). For the age group 15-39 years, the principal sources were the regional cancer registries in England and the national cancer registries of Scotland and Wales. Many young people with bone sarcomas are treated by members of the UKCCSG and included in the UKCCSG Register; for those aged 15 years and over, the UKCCSG Register was an independent source of ascertainment; UKCCSG patients below this age were already in the NRCT. Specialist bone tumour registers in several regions and the Birmingham Bone Tumour Service supplied lists of eligible cases. Lists of patients entered in national and international trials for OS and ES were provided by the Medical Research Council (MRC) Cancer Trials Office and the UKCCSG, respectively, and linked with registration records.

Incident cases of bone cancer during the study period were classified on the basis of the best available information on the diagnosis for each case.

There were 2843 patients with a malignant bone tumour diagnosed as a first cancer before age 40 years during 1980 1994. The 32 patients who had a bone cancer as a second or later malignancy are not considered here.

Osteosarcoma was the most common subgroup, accounting for 1349 cases $(47 \%)$. Incidence was highest at age 10-19 years. Overall, $59 \%$ of OSs were diagnosed in males. The proportion of males was highest at age 15-24 years (64\%), while among children aged under 10 years there was a slight female excess (55\%). Osteosarcoma is predominantly a tumour of the long bones of the limbs. In this series, $75 \%$ of cases with known primary site arose in the legs and $12 \%$ in the arms. Only $11 \%$ of primaries were in the axial skeleton. The proportion of axial primaries was higher at age 25 years and over $(28 \%)$.

Ewing's sarcoma, including peripheral primitive neuroectodermal tumour (pPNET) of bone, was the second most common subgroup, with $849(30 \%)$ cases. In the first 10 years of life it was the most frequent type of bone cancer. Incidence reached its peak at age 10-14 years and declined sharply throughout early adulthood. The overall male excess (58\%) was similar to that for OS, and it was less pronounced (53\%) among children aged under 15 years. The most frequent primary sites for ES were the leg (35\% of tumours of known primary site) and the pelvis $(26 \%)$. Pelvic primaries were extremely rare before the age of 5 years but otherwise there was little variation in primary site with age.

Chondrosarcoma accounted for 307 (11\%) cases, other specified tumours for $245(8 \%)$ and unspecified tumours for $93(3 \%)$.

The present analyses of patterns of care and survival are restricted to OS and ES.
Main (nonsurgical) treatment centre for clinical trial patients was defined as the hospital from which the patient was enrolled in the trial. For nontrial patients, it was defined as the highest level hospital (in the classification below) at which there was evidence from any data source that the patient received nonsurgical treatment within 2 months of diagnosis. Treatment centres were classified as follows:

BTS: the two supra-regional Bone Tumour Services in London and Birmingham;

UKCCSG: the 20 paediatric oncology centres affiliated to the UK Children's Cancer Study Group (from 1990, some London BTS patients were registered with the UKCCSG but for all the analyses presented here they have been counted as BTS);

Other teaching hospitals: the remaining 26 hospitals in geographical proximity to and attached to medical schools;

Nonteaching hospitals: the remaining 82 hospitals treating study patients.

Surgical centres were identified from registrations and grouped as BTS and all other hospitals.

All study patients in the NRCT for whom a death certificate has not been received are flagged in the National Health Service Central Registers (NHSCR). Death certificates for persons dying of neoplasms at age 15-19 years are also available from the NRCT. Study patients aged 15-39 years at diagnosis were submitted for flagging at NHSCR. NHSCR provided death certificates for flagged patients who had died, together with notifications of emigration resulting in loss to follow-up. All flagged patients not known to have died or emigrated were assumed to be alive on 31st January 2003. Follow-up information was available for 96\% (1297) of patients with OS and 98\% (831) of those with ES.

Survival rates were calculated by the Kaplan-Meier method and univariate analyses performed using the log-rank test (Peto et al, 1977). Multivariate analyses of survival were carried out using Cox's proportional hazards analysis (Cox, 1972). All survival analyses were carried out using the statistical software package Stata, Version 7 (StatCorp, College Station, TX, USA).

\section{RESULTS}

\section{Referral patterns}

Table 1 shows the numbers of patients with OS and Ewing's sarcoma classified by main treatment centre. Referral to BTS increased in successive periods, reaching $38 \%$ of patients for whom this information was known for OS and 30\% for ES by 1990-1994. Between 1980-1984 and 1990-1994, the proportions referred to nonteaching hospitals fell from 24 to $5 \%$ for OS and from 20 to $7 \%$ for ES. Referral to hospitals with fewer than two new study patients per year also fell, with the decrease being more marked for OS (from 36 to $10 \%$ ) than for ES (from 31 to 19\%). The proportion of patients at nonteaching centres increased with age for both diagnostic groups.

Information on surgical centre was available from 1982 onwards. Overall, 53\% (612/1151) of patients with OS were referred to a BTS for surgery. The proportion so referred increased from $35 \%$ in $1982-1984$ to $54 \%$ in $1985-1989$ and $65 \%$ in $1990-1994$. Referral rates by age were $55 \%$ at $0-9$ years, $65 \%$ at $10-14,52 \%$ at $15-19$ and $45 \%$ at $20-39$ years. For ES, local therapy has often been by radiotherapy alone for axial primaries (Craft et al, 1998) and also for many limb primaries until the mid 1980s (Craft et al, 1997). Surgical centre was therefore only analysed for patients with limb primaries diagnosed during 1985-1994. Among this group, 51\% (139 out of 274) were referred to a BTS for surgery. The referral rate varied little with age (results not shown). 
Table I Main treatment centre for patients with osteosarcoma and Ewing's sarcoma

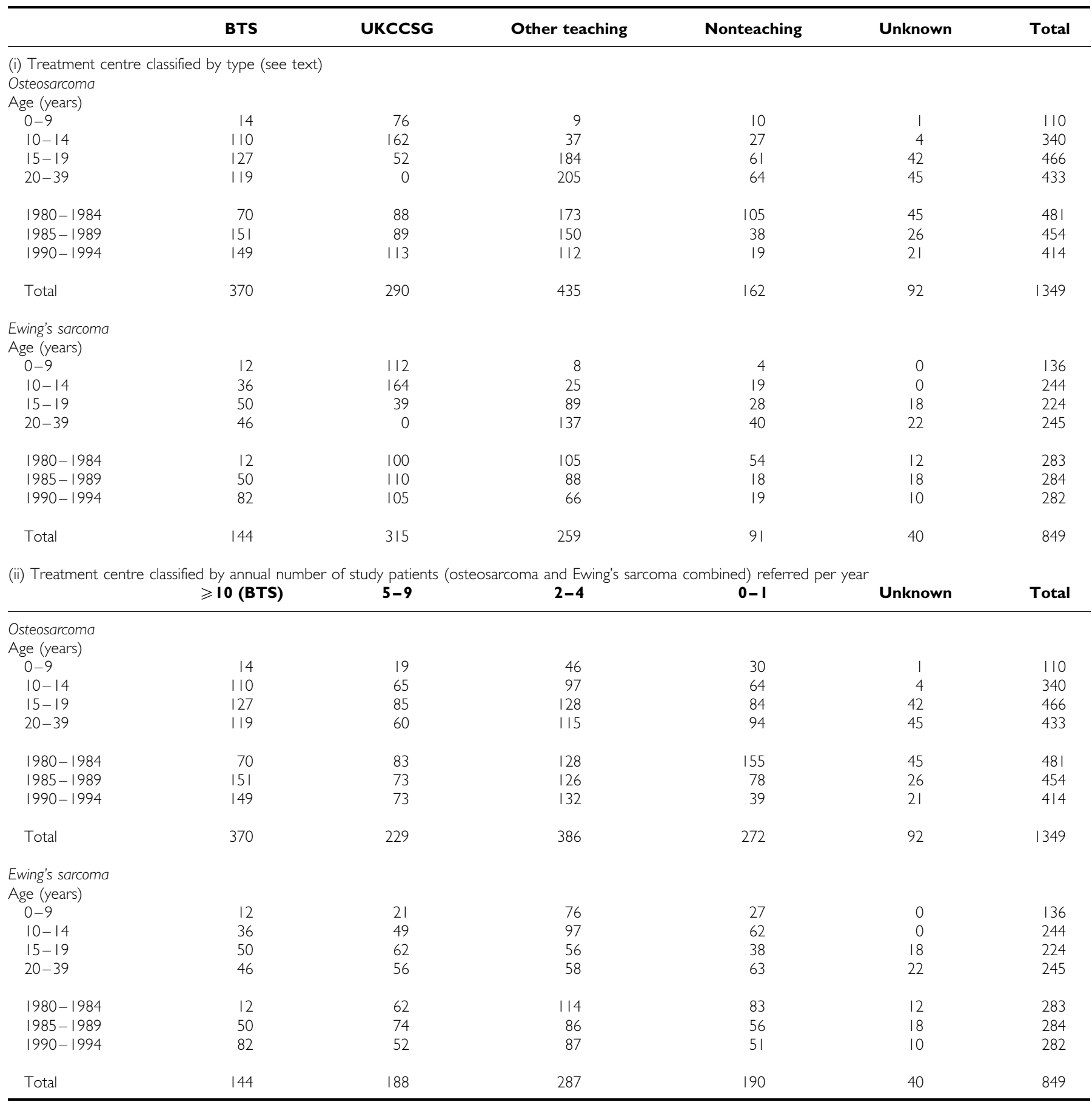

\section{Entry to national clinical trials}

During 1983-1986, there was one OS trial for which patients aged under 40 years with operable tumours were eligible (Bramwell et al, 1992), including those with metastases at diagnosis (Bramwell et al, 1997). While intended for patients with limb primaries, this trial also included a few with axial tumours. During 1987-1992, two trials were open simultaneously. The first was for patients with localised limb primaries (Souhami et al, 1997) and the second was for patients with metastatic disease or axial tumours (Voûte et al, 1999). Entry rates overall were similar in $1983-1986$ (47\%) and 1987-1992 (50\%). They were higher for children and adolescents aged under 20 years (55\%) than for patients aged 20-39 years (36\%). Entry rates were higher among BTS patients $(68 \%)$ than those treated elsewhere $(43 \%)$.

Three successive trials for ES were open during the study period. The first of these was the UKCCSG study ET-1, which actually began in 1978 (Craft et al, 1997). The entry rate during 1980-1986 was $27 \%$ overall, $43 \%$ for children aged under 15 years and $19 \%$ for adolescents aged 15-19 years. The upper age limit for the study was 40 years, but only $4 \%$ of patients aged $20-29$ years and none aged 30-39 were entered. Among children and adolescents, entry rates were much higher at (non-BTS) UKCCSG centres (59\%) than elsewhere (14\%). 
Table 2 Univariate analysis of survival by age, sex, primary site and year of diagnosis

\begin{tabular}{|c|c|c|c|c|c|c|c|c|c|c|}
\hline & \multicolumn{4}{|c|}{ Osteosarcoma } & \multirow[b]{2}{*}{$P$} & \multicolumn{4}{|c|}{ Ewing's sarcoma } & \multirow[b]{2}{*}{$P$} \\
\hline & $N$ & I year & 5 years & 10 years & & $N$ & I year & 5 years & 10 years & \\
\hline \multicolumn{11}{|l|}{ Age (years) } \\
\hline $0-4$ & 9 & 67 & 67 & 56 & 0.39 & 27 & 85 & 52 & 48 & $<0.0001$ \\
\hline $5-9$ & 99 & 91 & 58 & 55 & & 109 & 89 & 59 & 56 & \\
\hline $10-14$ & 340 & 86 & 45 & 43 & & 242 & 91 & 48 & 42 & \\
\hline $15-19$ & 446 & 85 & 47 & 41 & & 216 & 81 & 30 & 26 & \\
\hline $20-24$ & 206 & 84 & 52 & 45 & & 123 & 77 & 38 & 32 & \\
\hline $25-29$ & 82 & 79 & 48 & 45 & & 62 & 82 & 40 & 32 & \\
\hline $30-39$ & 115 & 90 & 56 & 49 & & 52 & 75 & 48 & 34 & \\
\hline \multicolumn{11}{|l|}{ Sex } \\
\hline Male & 759 & 85 & 47 & 41 & 0.031 & 485 & 83 & 43 & 37 & 0.61 \\
\hline Female & 538 & 86 & 53 & 49 & & 346 & 87 & 42 & 38 & \\
\hline \multicolumn{11}{|l|}{ Primary site } \\
\hline Skull & 52 & 94 & 67 & 67 & $<0.0001$ & 25 & 92 & 56 & 56 & $<0.0001$ \\
\hline Spine & 21 & 76 & 43 & 29 & & 58 & 79 & 43 & 36 & \\
\hline Ribs, sternum & 21 & 67 & 38 & 33 & & 88 & 86 & 45 & 38 & \\
\hline Pelvis & 55 & 64 & 24 & 21 & & 206 & 77 & 24 & 21 & \\
\hline Arm & 157 & 86 & 44 & 35 & & 102 & 88 & 53 & 47 & \\
\hline Hand & & & & & & | | & 100 & 73 & 64 & \\
\hline Leg & 964 & 87 & 51 & 47 & & 284 & 90 & 49 & 42 & \\
\hline Foot & II & 73 & 64 & 55 & & 24 & 88 & 46 & 42 & \\
\hline Unspecified & 16 & 69 & 50 & 44 & & 33 & 64 & 39 & 36 & \\
\hline \multicolumn{11}{|l|}{ Year of diagnosis } \\
\hline $1980-1984$ & 469 & 79 & 42 & 36 & $<0.0001$ & 279 & 84 & 31 & 26 & $<0.0001$ \\
\hline $1985-1989$ & 428 & 89 & 54 & 50 & & 274 & 84 & 46 & 40 & \\
\hline $1990-1994$ & 400 & 89 & 53 & 48 & & 278 & 86 & 51 & 45 & \\
\hline
\end{tabular}

Percentage survival rates at 1,5 and 10 years after diagnosis and $P$-value from log rank test for heterogeneity.

The second ES trial was run jointly by UKCCSG and MRC (Craft et al, 1998). The entry rate overall for 1987-1992 almost doubled to $52 \%$. Entry increased in all age groups below 30 years, reaching $72 \%$ for children under $15,56 \%$ for adolescents aged $15-19$ years and 33\% for young adults aged 20-29 years. The upper age limit was 30 years and there were no entries above that age. Entry rates from UKCCSG and BTS centres (73\%) were higher than elsewhere (19\%).

The third trial, EICESS-92, was an international collaboration between UKCCSG, MRC and the German Co-operative Ewing's Sarcoma Study Group (Schuck et al, 2003). The upper age limit was 40 years. During 1993-1994, the first 2 years that this trial was open, the overall entry rate rose to $62 \%$. This was largely due to an increase in the entry rate for children to $83 \%$. Entry rates were $84 \%$ at UKCCSG and BTS centres and 15\% elsewhere.

\section{Survival}

Table 2 shows the results of univariate analysis of survival by age, sex, primary site and year of diagnosis. Table 3 shows 5 year survival by period of diagnosis and age group. For OS diagnosed during 1990-1994, children aged under 10 years had a somewhat higher survival rate than older patients. Female subjects had a higher survival rate than males (Table 2). There was no evidence of a difference in survival between the sexes among children aged 0 14 years but female subjects had markedly higher survival in the older age groups. The variation in survival with age was present for both sexes, although less marked for female subjects (results not shown). Patients with skull tumours had an exceptionally high survival rate. Those with primaries in other axial sites (spine, ribs and sternum, pelvis) or in the arm had lower than average survival. Five-year survival rates during 1980-1984, 1985-1989 and 19901994 were $42 \%$ (95\% CI: 37, 46), 54\% (95\% CI: 50, 59) and 53\%
Table 3 Five-year survival (\%) by calendar period and age at diagnosis

Osteosarcoma

Ewing's sarcoma

Age at diagnosis (years)

$\begin{array}{llllllll}0-9 & 10-14 & 15-19 & 20-39 & 0-9 & 10-14 & 15-19 & 20-39\end{array}$

Year of diagnosis

$\begin{array}{lllllllll}1980-1984 & 45 & 39 & 41 & 45 & 40 & 37 & 15 & 35 \\ 1985-1989 & 54 & 51 & 54 & 57 & 67 & 49 & 26 & 47 \\ 1990-1994 & 71 & 48 & 48 & 55 & 72 & 59 & 47 & 39\end{array}$

(95\% CI: 48, 57), respectively (Figure 1). The pattern of substantial increase in survival between 1980-1984 and 1985-1989 but no further improvement in 1990-1994 was similar for all age groups above age 10 years.

For ES, children aged under 15 years had higher survival than other patients. There was no difference in survival between male and female subjects. Pelvic primary site was associated with poor survival. The small number of patients with skull or hand primaries had a good prognosis. Survival for other axial sites was similar to that for limb primaries. Five-year survival rates during 1980-1984, 1985-1989 and 1990-1994 were 31\% (95\% CI: $26,37), 46 \%(95 \%$ CI: 40,51$)$ and $51 \%$ (95\% CI: 45,57$)$, respectively (Figure 2). This pattern of steadily increasing survival throughout the study period was present in each age group below 20 years, but above that age there was rather little change with calendar period.

Table 4 shows 5-year survival for patients at different categories of main treatment centre by period of diagnosis. For OS, survival 
during 1980-1984 was higher at BTS and UKCCSG centres than elsewhere. In 1985-1989, only the nonteaching hospitals had lower survival and in 1990-1994 there was relatively little variation.

For ES in all three calendar periods, survival was lower among patients treated at nonteaching hospitals. During 1985-1994, BTS and UKCCSG centres had higher survival rates than other teaching hospitals. Apart from the very few children aged under 10 years, patients of all ages at nonteaching hospitals had a lower survival rate. The higher survival at BTS centres was most marked for the age group $10-14$ years.

Five-year survival of patients with OS who had surgery at a BTS centre in 1982-1984 was 59\%, significantly higher than for those having surgery elsewhere $(39 \%, \log$ rank $P=0.001)$. More recently, there was no significant difference in survival between BTS and other surgical centres (1985-1989, 58 vs 51\%, $P=0.26$; $1990-1994$, 51 vs $55 \%, P=0.85)$.

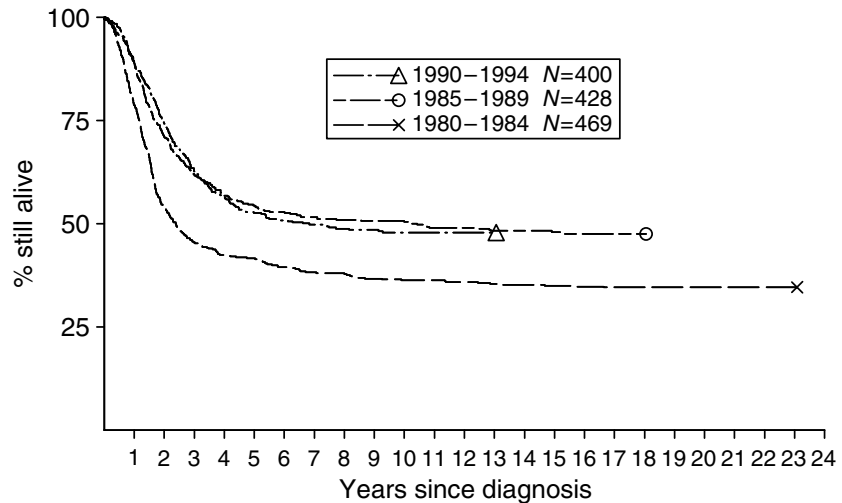

Figure I Survival of patients with OS diagnosed at age under 40 years during 1980-1994, by calendar period of diagnosis.

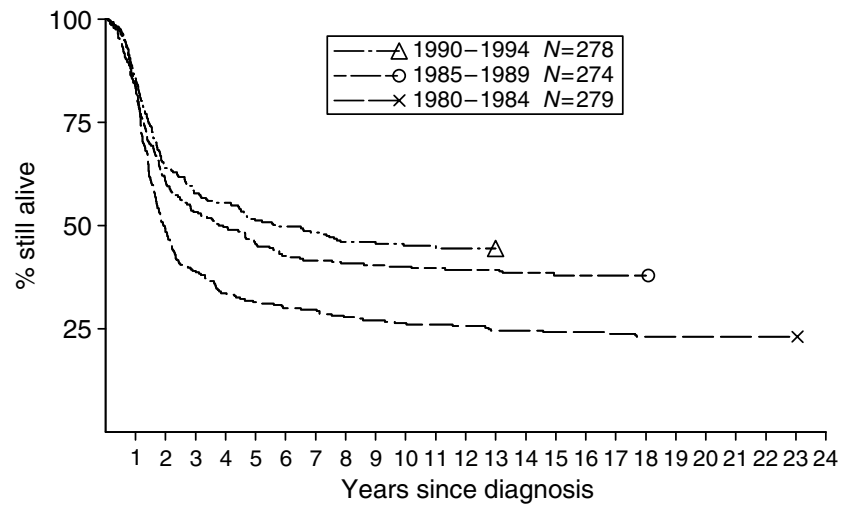

Figure 2 Survival of patients with ES diagnosed at age under 40 years during 1980-1994, by calendar period of diagnosis.
For OS, there was no significant difference in survival between trial and nontrial patients diagnosed during 1983-1986 (5-year survival 52 and $50 \%$, respectively, $\log$ rank $P=0.21$ ) or $1987-1992$ (5-year survival 50 and $55 \%, P=0.45$ ).

Table 5 shows 5-year survival of trial and nontrial patients with ES. Year of diagnosis was regrouped as 1980-1986, 1987-1992, $1993-1994$, to correspond with the periods when successive trials were open. Survival was higher for trial than for nontrial patients during the eras of the three successive trials (Figure 3). For patients aged under 20 years, survival was higher among those in the trials, but above that age there was no difference in survival between trial and nontrial patients.

In the univariate analysis of OS, the effects of main treatment centre and surgical centre differed for patients diagnosed before and after the end of 1984. Multivariate analysis was therefore performed for patients diagnosed during 1985-1994. The variables in the model were sex, age, primary site, main treatment centre and surgical centre. Results are shown in Table 6. Male sex and primary site in the spine, ribs and sternum or in the pelvis were confirmed as adverse prognostic factors. Compared with nonteaching hospitals as reference category of main treatment centre, survival of patients at UKCCSG and other non-BTS teaching hospitals was significantly higher.

For ES also, the effect of main treatment centre differed between 1980-1984 and 1985-1994, and multivariate analysis was therefore restricted to the latter period. Trial status was included in the model as it was significant in univariate analysis. Table 7 shows the results of two analyses, the first for all patients and the second only for those with a limb primary; surgical centre was included in the second analysis. Age 10-24 years and pelvic primary site were confirmed as adverse prognostic factors. Survival was significantly higher at BTS, UKCCSG and teaching hospital main treatment centres than at nonteaching hospitals. In a similar model in which treatment centre caseload was substituted for type of main treatment centre, those with fewer than two study patients per year had a significantly lower survival rate. In the analysis of

Table 5 Five-year survival (\%) for Ewing's sarcoma trial and nontrial patients by calendar period and age at diagnosis, 1980-1994

\begin{tabular}{lrccc}
\hline & $\mathbf{N}$ & Trial & Non-trial & $\boldsymbol{P}$ \\
\hline Year of diagnosis & & & & \\
1980-1986 & 386 & 42 & 30 & 0.0047 \\
1987-1992 & 355 & 59 & 42 & 0.0001 \\
1993-1994 & 90 & 54 & 43 & 0.093 \\
Age (years) & & & & \\
$0-9$ & 136 & 68 & 44 & 0.0005 \\
$10-14$ & 242 & 52 & 40 & 0.024 \\
$15-19$ & 216 & 48 & 19 & $<0.0001$ \\
$20-24$ & 123 & 38 & 38 & 0.83 \\
$25-39$ & 114 & 43 & 44 & 0.72 \\
\hline
\end{tabular}

Table 4 Five-year survival (\%) for patients at different categories of main treatment centre by calendar period, 1980-1994

\begin{tabular}{|c|c|c|c|c|c|c|c|}
\hline \multicolumn{8}{|l|}{ Osteosarcoma } \\
\hline $1980-1984$ & 469 & 50 & 51 & 38 & 37 & 34 & 0.0092 \\
\hline $1990-1994$ & 400 & 49 & 55 & 55 & 44 & 56 & 0.49 \\
\hline \multicolumn{8}{|l|}{ Ewing's sarcoma } \\
\hline $1980-1984$ & 279 & 33 & 40 & 31 & 21 & 8 & 0.0003 \\
\hline
\end{tabular}




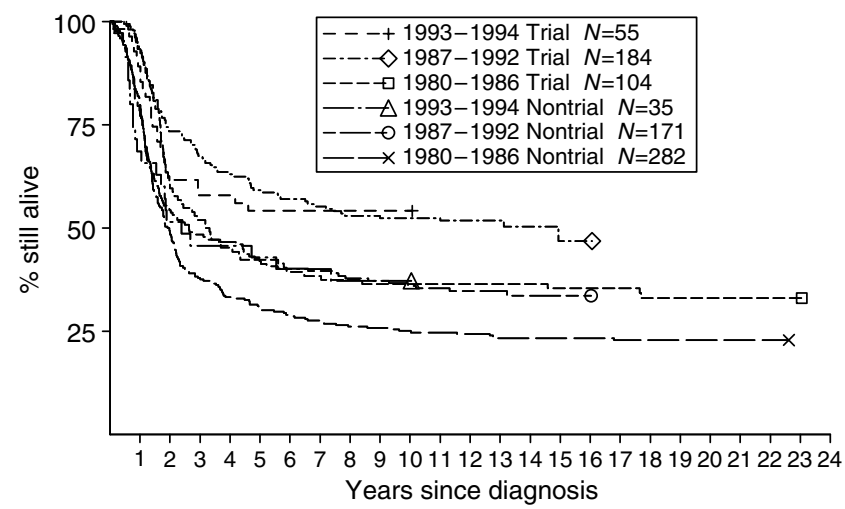

Figure 3 Survival of patients with ES diagnosed at age under 40 years during 1980-1994, by calendar period of diagnosis and trial status. The periods 1980-1986, 1987-1992 and 1993-1994 correspond, respectively, to periods of entry to the first UKCCSG study, the second UKCCSGMRC study and the international trial EICESS-92.

Table 6 Results of Cox proportional hazards analysis for osteosarcoma diagnosed during 1985-1994

\begin{tabular}{|c|c|}
\hline & HR (95\% Cl) \\
\hline \multicolumn{2}{|l|}{ Sex } \\
\hline Male & I (reference) \\
\hline Female & $0.72(0.59,0.88)$ \\
\hline \multicolumn{2}{|l|}{ Age (years) } \\
\hline $0-9$ & I (reference) \\
\hline $10-14$ & $1.30(0.87,1.94)$ \\
\hline $15-19$ & $1.13(0.74,1.72)$ \\
\hline $20-39$ & $1.06(0.68,1.63)$ \\
\hline \multicolumn{2}{|l|}{ Primary site } \\
\hline Skull & $0.76(0.43,1.37)$ \\
\hline Spine, ribs, sternum & $1.84(1.10,3.10)$ \\
\hline Pelvis & $3.04(2.07,4.46)$ \\
\hline Upper limb & $1.10(0.82,1.47)$ \\
\hline Lower limb & I (reference) \\
\hline Unspecified & $2.34(1.13,4.84)$ \\
\hline \multicolumn{2}{|l|}{ Main treatment centre } \\
\hline BTS & $0.86(0.56,1.32)$ \\
\hline UKCCSG & $0.60(0.39,0.93)$ \\
\hline Teaching & $0.69(0.47,1.00)$ \\
\hline Nonteaching & I (reference) \\
\hline Unknown & $0.42(0.23,0.75)$ \\
\hline \multicolumn{2}{|l|}{ Surgical centre } \\
\hline BTS & I (reference) \\
\hline Other & $1.15(0.88,1.52)$ \\
\hline
\end{tabular}

$\mathrm{HR}=$ Hazard ratio.

patients with limb primaries, the adverse effect of age 10-24 years remained. Main treatment centre, surgical centre and trial status were all nonsignificant.

\section{DISCUSSION}

Survival from both OS and ES increased markedly between 1980 1984 and 1985-1989. In the next 5 years, survival increased further for patients diagnosed with ES before the age of 20 years, although survival of those diagnosed at age 20-39 years fell back to near the level for 1980-1984. Among patients with OS diagnosed during
Table 7 Results of Cox proportional hazards analysis for Ewing's sarcoma diagnosed during 1985-1994

\begin{tabular}{|c|c|c|}
\hline & \multicolumn{2}{|c|}{ HR $(95 \% \mathrm{Cl})$} \\
\hline & (i) All primary sites & (ii) Limb primaries only \\
\hline \multicolumn{3}{|l|}{ Sex } \\
\hline Male & I (reference) & I (reference) \\
\hline Female & $0.94(0.75,1.18)$ & $0.89(0.63,1.27)$ \\
\hline \multicolumn{3}{|l|}{ Age (years) } \\
\hline $0-9$ & I (reference) & I (reference) \\
\hline $10-14$ & $1.61(1.04,2.50)$ & $2.05(1.06,3.97)$ \\
\hline $15-19$ & $2.04(1.27,3.28)$ & $3.08(1.50,6.31)$ \\
\hline $20-24$ & $2.09(1.21,3.61)$ & $3.18(1.42,7.10)$ \\
\hline $25-39$ & $1.63(0.94,2.82)$ & $1.95(0.82,4.61)$ \\
\hline \multicolumn{3}{|l|}{ Primary site } \\
\hline Skull & $0.46(0.19,1.13)$ & - \\
\hline Spine, ribs, sternum & $1.20(0.87,1.66)$ & - \\
\hline Pelvis & $1.64(1.24,2.18)$ & - \\
\hline Upper limb & $0.87(0.59,1.28)$ & $0.89(0.61,1.31)$ \\
\hline Lower limb & I (reference) & I (reference) \\
\hline Unspecified & $1.18(0.69,2.00)$ & - \\
\hline \multicolumn{3}{|l|}{ Main treatment centre } \\
\hline BTS & $0.44(0.27,0.7 I)$ & $0.54(0.24,1.20)$ \\
\hline UKCCSG & $0.50(0.30,0.84)$ & $0.57(0.24,1.32)$ \\
\hline Teaching & $0.64(0.43,0.97)$ & $0.58(0.29,1.15)$ \\
\hline Non-teaching & I (reference) & I (reference) \\
\hline Unknown & $0.42(0.22,0.80)$ & $0.84(0.29,2.48)$ \\
\hline \multicolumn{3}{|l|}{ Surgical centre } \\
\hline BTS & - & I (reference) \\
\hline Other & - & $1.32(0.82,2.12)$ \\
\hline \multicolumn{3}{|l|}{ Trial status } \\
\hline Trial & I (reference) & I (reference) \\
\hline Nontrial & $1.28(0.97,1.68)$ & $1.31(0.87,1.97)$ \\
\hline
\end{tabular}

1990-1994, by contrast, only those aged under 10 years experienced any additional increase in survival compared with 1980-1989. Overall, these results are consistent with the contemporaneous decrease in population mortality from bone cancer, which was more marked at younger ages.

The favourable prognosis for craniofacial OS is in agreement with clinical reports (Gadwal et al, 2001; Smith et al, 2003). Data from the SEER Program cancer registries in the US showed no major difference compared with long bone primaries in an analysis including patients of all ages, although this did not allow for age, but the poor prognosis for pelvic OS was confirmed (Dorfman and Czerniak, 1995). In a more recent study of patients aged under 20 years, survival did not differ substantially by site, but no details were given (Gurney et al, 1999). In a recent clinical series, $40 \%$ of patients aged under 40 years with a pelvic OS had an inoperable primary or distant metastases (Grimer et al, 1999).

Among patients aged under 20 years with OS, we found that survival of those aged 10-14 years was lower than for younger children but there was no further deterioration of prognosis in the 15- 19 year age group. In the USA, by contrast, survival was worse at age 15-19 than at age 10-14 years and children aged under 10 years at diagnosis also had a somewhat lower survival rate, particularly before 1985 (Gurney et al, 1999). The effects of age on survival in clinical series have been similarly inconsistent (Nagarajan et al, 2003).

Survival from OS was significantly higher for female than for male subjects. This is consistent with the higher metastasis-free survival for female subjects in the Scandinavian Sarcoma Group 
studies, in which it was suggested that that may be due to some unknown gender-dependent genetic factor (Smeland et al, 2003).

We found no difference in survival from ES between male and female subjects, whereas in the SEER data 5-year relative survival rates were $35 \%$ for males and $52 \%$ for female subjects (all ages, $1973-1987$ ) and $50 \%$ for males, $68 \%$ for female subjects (age $0-19$ years, 1975-1994). Survival rates from ES in the US have not been published for all ages, but among patients aged under 20 years pelvic primary site was associated with a low 5-year survival of under 35\% (Gurney et al, 1999). The poor prognosis for pelvic tumours was also found in a large, combined clinical trial series from the UK and Germany and may be attributable to the larger tumour volume typical of that site (Cotterill et al, 2000).

A striking feature of the present study was the relation of survival to age for ES. The prognosis at age 15 years and over was much worse than for children below that age. In the UK - Germany clinical trial series, the age-related difference in survival was most marked with a cutoff point of 15 years (Cotterill et al, 2000). In the US, survival at age 10-14 years was lower than that for younger children, but adolescents aged 15-19 years had very similar survival to the 10-14 years age group (Gurney et al, 1999). In a study of patients with ES or pPNET treated on the adult sarcoma unit of the Royal Marsden Hospital, survival was higher for patients aged 20 years and over than for those aged 15-19 years (Verrill et al, 1997). That study only included 59 patients overall, and 51 aged 15-39 years. Moreover, patients with extra-osseous primaries were also included, although tissue of origin was not found to be of prognostic importance. In the present much larger study, there was a suggestion of increasing survival above age 20 years but this fell far short of statistical significance.

Survival of children aged under 15 years with OS during 19771980 did not vary between paediatric oncology centres and other hospitals, whereas in 1981-1984 there was a substantial increase in survival at paediatric oncology centres which did not take place elsewhere (Stiller, 1988). In the present study, covering 1980-1994, there was some indication that survival was higher at specialist centres than at other hospitals, but the differences were not always statistically significant. This is similar to the finding of nonsignificantly higher survival at major centres by Gill et al (1988), although their study largely related to an earlier period when modern combination chemotherapy for OS was not widely used and survival was much lower. During the 10 years for which data were available from national trials, slightly under half of the patients with OS in this study were entered in a trial. Survival was very similar for trial and nontrial patients. To be eligible for inclusion in the trials, patients had to have operable, high-grade OS and not to have other medical conditions which might preclude them from receiving treatment according to the protocol, and the maximum interval from biopsy to randomisation was 35 days (Bramwell et al, 1992; Souhami et al, 1997; Voûte et al, 1999). Most of these criteria would tend to exclude patients with a worse prognosis, although the histological criterion would exclude lower grade tumours with a better prognosis. There has been little progress in treatment and survival for OS since the early 1980s. It seems likely that trial and nontrial patients would have been similarly treated in the same hospitals and it is therefore not surprising that they should have similar survival rates. In the US Multi-Institutional Osteosarcoma Study, survival was similar for randomised patients and those who declined randomisation but were treated according to protocol (Link et al, 1991). The higher survival rate for patients who had surgery at a supraregional bone tumour centre was confined to the early years of the study, with little sign of any variation more recently. Within the European Intergroup trials during 1983-1993, survival rates were identical for patients treated at each of the three largest surgical centres despite different treatment policies (Grimer et al, 2002).

Children aged under 15 years with ES had a higher survival rate at paediatric oncology centres compared with other hospitals throughout the period 1977-1984 (Stiller, 1988). In the present study, survival was higher at specialist bone tumour treatment centres and paediatric oncology centres than at other hospitals, including other teaching hospitals. Survival of children and adolescents from ES was consistently higher throughout the study period for patients entered in national trials than for those who were not entered. Tumour stage was not available for this study and it is theoretically possible that any apparent effects of treatment centre and trial status on survival were due to confounding of these variables with stage. However, as primary site was an important prognostic factor associated with tumour burden, and trials were open for patients with both localised and metastatic disease, this seems unlikely. There was a maximum interval of 3 weeks between diagnosis and starting treatment for patients to be eligible for EICESS-92 (Paulussen et al, 2001), but no maximum period between diagnosis and starting treatment was specified for the two earlier trials (Craft et al, 1997; Craft et al, 1998). Patients with any primary site and those with metastatic disease at diagnosis were eligible for all three trials.

Our study has several strengths. We analysed a large series of patients from population-based cancer registries that would not be subject to the selection bias that can affect studies based on hospital data. This was a national study with the ability to describe and analyse patterns of care and survival for the whole country. While it might be possible to obtain more detailed data in a study of a smaller geographical area, such an area might have atypical patterns of care. Follow-up through national record systems was virtually complete. Information on place of treatment was available for the great majority of patients and trial status was determined by direct linkage with clinical trial databases.

The study also has a number of limitations. Information on stage of disease was not available and therefore we could not identify patients with an obviously poor outlook at diagnosis who may not have been referred to a tertiary centre or entered in a trial for that reason. If stage had been available, this information would not itself have been completely reliable as it need not have been based on identical investigations in every case. We were able, however, to make some allowance for extent of disease by using information on primary site, which is associated with tumour burden in both OS and ES. The effects of trial status and treatment centre in multivariate survival analyses which also included primary site were broadly similar to those in the univariate analyses. The most recent patients in the study were diagnosed just over 10 years ago. Meanwhile, entry rates to clinical trials could have increased, referral patterns could have changed and standards of treatment could have improved, especially in nonteaching hospitals. Survival studies are necessarily historical, however, and the results of clinical trials that were open at the end of our study period are yet to be published. Only a further study could determine whether patterns of care have changed more recently and, if so, how they have influenced survival.

In conclusion, within the limitations of an analysis of historic data with incomplete allowance for confounding factors, this study provides evidence of higher survival rates at tertiary centres for patients with both of the main types of bone sarcoma diagnosed at ages up to 40 years.

\section{ACKNOWLEDGEMENTS}

This project was funded by a grant from the NHS Executive National Cancer Research and Development Programme. The Childhood Cancer Research Group is supported by the Departments of Health for England, Scotland and Wales. The views expressed here are not necessarily those of the NHS Executive or of the Departments of Health. We are grateful to the following who provided notifications of cases of bone cancer directly to this study or to the National Registry of Childhood Tumours: Office for 
National Statistics; Northern and Yorkshire Cancer Registry and Information Service; Trent Cancer Registry; East Anglia Cancer Registry; Thames Cancer Registry; Oxford Cancer Intelligence Unit; South and West Cancer Intelligence Unit; West Midlands Cancer Intelligence Unit; Merseyside and Cheshire Cancer Registry; North Western Cancer Registry; Scottish Cancer Registry; Welsh Cancer Intelligence and Surveillance Unit; UK Children's Cancer Study Group; Northern Region Young Persons' Malignant

\section{REFERENCES}

Bramwell VHC, Burgers M, Sneath R, Souhami R, van Oosterom AT, Voûte PA, Rouesse J, Spooner D, Craft AW, Somers R, Pringle J, Malcolm AJ, van der Eijken J, Thomas D, Uscinska B, Machin D, van Glabbeke M (1992) A comparison of two short intensive adjuvant chemotherapy regimens in operable osteosarcoma of limbs in children and young adults: The first study of the European Osteosarcoma Intergroup. J Clin Oncol 10: 1579 - 1591

Bramwell VHC, Burgers MV, Souhami RL, Taminiau AHM, van der Eijken JW, Craft AW, Malcolm AJ, Uscinska B, Kirkpatrick AL, Machin D, Van Glabbeke MM (1997) A randomized comparison of two short intensive chemotherapy regimens in children and young adults with osteosarcoma: results in patients with metastases: a study of the European Osteosarcoma Intergroup. Sarcoma 1: $155-160$

Coleman MP, Babb P, Damiecki P, Grosclaude P, Honjo S, Jones J, Knerer G, Pitard A, Quinn M, Sloggett A, De Stavola B (1999) Cancer Survival Trends in England and Wales 1971-1995 Deprivation and NHS Region. London: The Stationery Office

Cotterill SJ, Ahrens S, Paulussen M, Jürgens HF, Voûte PA, Gadner H, Craft AW (2000) Prognostic factors in Ewing's tumor of bone: analysis of 975 patients from the European Intergroup Cooperative Ewing's Sarcoma Study Group. J Clin Oncol 18: $3108-3114$

Cox DR (1972) Regression models and life tables. $J$ R Stat Soc B 34: $187-220$

Craft A, Cotterill S, Malcolm A, Spooner D, Grimer R, Souhami R, Imeson J, Lewis I (1998) Ifosfamide-containing chemotherapy in Ewing's sarcoma: the second United Kingdom Childrens's Cancer Study Group and the Medical Research Council Ewing's Tumor Study. J Clin Oncol 16: $3628-3633$

Craft AW, Cotterill SJ, Bullimore JA, Pearson D (1997) Long-term results from the first UKCCSG Ewing's Tumour Study (ET-1). Eur J Cancer 33: $1061-1069$

Dorfman HD, Czerniak B (1995) Bone cancers. Cancer 75: 203-210

Draper GJ (1985) The aetiology and epidemiology of bone and soft-tissue sarcomas. In Bone Tumours and Soft-Tissue Sarcomas, D'Angio GJ, Evans AE. (eds) pp 1-13. London: Edward Arnold

Gadwal SR, Gannon FH, Fanburg-Smith JC, Becoskie EM, Thompson LDR (2001) Primary osteosarcoma of the head and neck in pediatric patients: a clinicopathologic study of 22 cases with a review of the literature. Cancer 91: $598-605$

Gill M, Murrells T, McCarthy M, Silcocks P (1988) Chemotherapy for the primary treatment of osteosarcoma: population effectiveness over 20 years. Lancet 1: $689-692$

Grimer RJ, Carter SR, Tillman RM, Spooner D, Mangham DC, Kabukcuoglu Y (1999) Osteosarcoma of the pelvis. J Bone Joint Surg Br 81: $796-802$

Grimer RJ, Taminiau AM, Cannon SR (2002) Surgical outcomes in osteosarcoma. J Bone Joint Surg 84-B: 395-400

Gurney JG, Swensen AR, Bulterys M (1999) Malignant bone tumours. In Cancer Incidence and Survival among Children and Adolescents: United States SEER Program 1975-1995, Gloeckler Ries LA, Smith MA, Gurney JG, Linet M, Tamra T, Young JL, Bunin GR. (eds) pp 99-110. Bethesda, MD: NIH Pub No 99-4649

Hartley AL, Blair V, Harris M, Birch JM, Banerjee SS, Freemont AJ, McClure J, McWilliam LJ (1991) Sarcomas in North West England: II Incidence. Br J Cancer 64: $1145-1150$
Disease Registry; Yorkshire Specialist Register of Cancer in Children and Young People; West Midlands Regional Children's Tumour Registry; Manchester Children's Tumour Registry; Northern Region Bone Tumour Registry; Yorkshire Bone Tumour Registry; Bristol Bone Tumour Registry; Scottish Bone Tumour Registry; MRC Cancer Trials Unit. We thank the NHS Central Registers for flagging of study members and copies of death certificates.

Hartley AL, Blair V, Harris M, Birch JM, Banerjee SS, Freemont AJ, McClure J, McWilliam LJ (1992) Sarcomas in North West England: III Survival. $\mathrm{Br}$ J Cancer 66: 685-691

Link MP, Goorin AM, Horowitz M, Meyer WH, Belasco J, Baker A, Ayala A, Shuster J (1991) Adjuvant chemotherapy of high-grade osteosarcoma of the extremity. Updated results of the Multi-Institutional Osteosarcoma Study. Clin Orthop Relat Res 270: 8-14

Nagarajan R, Weigel BJ, Thompson RC, Perentesis JP (2003) Osteosarcoma in the first decade of life. Med Pediatr Oncol 41: 480-483

Paulussen M, Ahrens S, Lehnert M, Taeger D, Hense HW, Wagner A, Dunst J, Harms D, Reiter A, Henze G, Niemeyer C, Göbel U, Kremens B, Fölsch UR, Aulitzky WE, Voûte PA, Zoubek A, Jürgens H (2001) Second malignancies after Ewing tumor treatment in 690 patients from a cooperative German/Austrian/Dutch study. Ann Oncol 12: 1619-1630

Peto R, Pike MC, Armitage P, Breslow NE, Cox DR, Howard SV, Mantel N, McPherson K, Peto J, Smith PG (1977) Design and analysis of randomized clinical trials requiring prolonged observation of each patient. II. Analysis and examples. Br J Cancer 35: 1-39

Schuck A, Ahrens S, Paulussen M, Kuhlen M, Könemann S, Rübe C, Winkelmann W, Kotz R, Dunst J, Willich N, Jürgens H (2003) Local therapy in localized Ewing tumors: results of 1058 patients treated in the CESS 81, CESS 86, and EICESS 92 trials. Int J Radiat Oncol Biol Phys 55: $168-177$

Smeland S, Müller C, Alvegard TA, Wiklund T, Wiebe T, Björk O, Stenwig AE, Willén H, Holmström T, Follerås G, Brosjö O, Kivioja A, Jonsson K, Monge O, Sæter G (2003) Scandinavian Sarcoma Group Osteosarcoma Study SSG VIII: prognostic factors for outcome and the role of replacement salvage chemotherapy for poor histological responders. Eur J Cancer 39: 488-494

Smith RB, Apostolakis LW, Karnell LH, Koch BB, Robinson RA, Zhen W, Menck HR, Hoffman HT (2003) National Cancer Data Base report on osteosarcoma of the head and neck. Cancer 98: 1670-1680

Souhami RL, Craft AW, van der Eijken JW, Nooij M, Spooner D, Bramwell VHC, Wierzbicki R, Malcolm AJ, Kirkpatrick A, Uscinska BM, van Glabbeke M, Machin D (1997) Randomised trial of two regimens of chemotherapy in operable osteosarcoma: a study of the European Osteosarcoma Intergroup. Lancet 350: $911-917$

Stiller CA (1988) Centralisation of treatment and survival rates for cancer. Arch Dis Child 63: 23-30

Stiller CA (1994) Population based survival rates for childhood cancer in Britain, 1980 -91. BMJ 309: $1612-1616$

Stiller CA, Allen MB, Eatock EM (1995) Childhood cancer in Britain; the national registry of childhood tumours and incidence rates 1978-1987. Eur J Cancer 31: 2028-2034

Stiller CA, Bunch KJ (1990) Trends in survival for childhood cancer in Britain diagnosed 1971-85. Br J Cancer 62: 806-815

Verrill MW, Judson IR, Harmer CL, Fisher C, Thomas JM, Wiltshaw E (1997) Ewing's sarcoma and primitive neuroectodermal tumor in adults: are they different from Ewing's sarcoma and primitive neuroectodermal tumor in children? J Clin Oncol 15: 2611-2621

Voûte PA, Souhami RL, Nooij M, Somers R, Cortés-Funes H, van der Eijken JW, Pringle J, Hogendoorn PCW, Kirkpatrick A, Uscinska BM, van Glabbeke M, Machin D, Weeden S, on behalf of the European Osteosarcoma Intergroup (EOI) (1999) A phase II study of cisplatin, ifosfamide and doxorubicin in operable primary, axial skeleton and metastatic osteosarcoma. Ann Oncol 10: 1211-1218 